\title{
From:
}

Skills Development and Training in SMEs

Access the complete publication at:

\section{Formal training and skills development: The state of play}

Cristina Martinez-Fernandez, Samantha Sharpe 
This document and any map included herein are without prejudice to the status of or sovereignty over any territory, to the delimitation of international frontiers and boundaries and to the name of any territory, city or area. 
PART I

Chapter 1

\section{Formal training and skills development: The state of play}

by

Cristina Martinez-Fernandez and Samantha Sharpe

This chapter analyses formal training activities within small and medium sized enterprises (SMEs). It is anticipated that across Europe, most new jobs will be within knowledge and other skills intensive jobs. Results of the Continuing Vocational Training Surveys over the last few years are analysed, to determine levels of participation by small, medium and large firms in training and skills development activities, and the potential effects these training programmes will have on the future competitiveness of the SMEs. Areas investigated include: initial Vocational Education and Training (VET), specifically apprenticeships; and continuing VET (primarily that financed by the workplace).

From these results, policy implications are suggested, which are designed to enable SMEs to utilise the findings to develop or improve their current training regimes, and to draw the attention of government agencies to how best to positively influence these companies. 


\section{Company size and training activities}

Company size is an important determinant of the level of participation in workforce development, specifically of labour force training and skills upgrading activities. Consistently, data across OECD countries show that SMEs participate $50 \%$ less in training activities than large firms. Drivers for these lower levels of participation include a lack of critical mass within the firm enabling them to afford (both financial costs and the cost of employees' time) and access formal training opportunities. Instead, SMEs are more inclined to participate in knowledge intensive activities as a way of learning new techniques or new ways to operate. This includes learning by interacting with consultants, suppliers or clients; or attending conferences, meetings or internal activities such as quality control activities. These activities, however, do not carry formal qualifications or standard training certificates and tend to benefit managers, business owners and the higher educated staff members.

This chapter analyses formal training activities within SMEs, drawing on official statistics, as part of the Leveraging Training and Skills Development in SMEs (TSME) project. ${ }^{1}$ As formal training activities, particularly those activities leading to recognised qualifications, are more easily captured through official statistical collections, this chapter focuses more closely on these. Chapters two and three provide detailed results from a specially designed SME training survey conducted in six OECD countries; Belgium, the United Kingdom, Turkey, New Zealand, Poland and Canada. This survey focuses more closely on informal/alternative training activities and the outcomes for which firms are looking and have achieved from their training activities.

\section{Box 1.1. Defining formal and informal training}

Formal training refers to learning that occurs in an organised and structured environment (e.g. in an education or training institute or on the job) and is explicitly designated as learning (in terms of objectives, time or resources). Formal learning is intentional from the learner's point of view. It typically leads to validation and certification.

Informal training refers to learning resulting from daily activities related to work, family or leisure. It is not organised or structured in terms of objectives, time or learning support. Informal learning is, in most cases, unintentional from the learner's perspective.

Source: Cedefop (European Centre for the Development of Vocational Training) (2010), Jobs in Europe to become more knowledge and skills-intensive, Cedefop Briefing Note, February 2010, Cedefop, Thessaloniki (Pylea).

According to a recent report by Cedefop (European Centre for the Development of Vocational Training), Europe will generate around seven million jobs net (job creation minus job losses) by 2020. Most of these new jobs ( 8.5 million plus) will be in knowledge and skills intensive occupations, meaning that the demand and need for skills (including formal training and qualifications) will continue to rise (Cedefop, 2010). The recognition of the growing importance of more and more skills is in contrast to the fact that enterprises 
with less than 50 employees provide significantly less employee training than larger firms (OECD, 2008, 2010). This remains true even for countries known for their strong training cultures, such as Denmark, the Netherlands, Norway and Sweden (OECD, 2010).

\section{Box 1.2. Defining vocational education and training}

Vocational education and training (VET) includes education and training programmes designed for, and typically leading to, a particular job or type of job. It normally involves practical training as well as the learning of relevant theory. It is distinct from academic education - for example mathematics, which is relevant to a very wide range of jobs. In the United States the usual term for vocational education and training is career and technical education (CTE). Education and training for some high level professions such as medicine and law meets the definition of VET but are not normally described as VET.

Initial VET includes programmes mainly designed for and used by young people (aged 30 and under) at the beginning of their careers and commonly before entering the labour market. It includes many upper secondary and tertiary programmes. Continuing VET are all other types of VET, including enterprise training of employees and training provided specifically for those who have lost their jobs.

These definitions and distinctions inevitably leave some blurred edges, since programmes can meet some of the relevant criteria but not all of them (for example, programmes designed for direct labour market entry but which rarely result in that outcome).

Source: OECD (2009), Learning for Jobs, Initial Report, OECD, Paris.

Continuing VET (CVET) can be further refined into categories on the basis of how the training is funded (by individuals, by public authorities, or by enterprises). This study is interested in training that is provided in the context of the work environment, therefore, the focus of this report is on this third category of Continuing VET - in which the training is in part or wholly financed by the company, and/or conducted by employees as part of their paid employment. Apprenticeships, which fall into the Initial VET category, are however, an important source of employee funded and conducted training, especially for SMEs. Therefore, discussion of this form of initial training is also presented.

One of the principal sources of data on Continuing VET within enterprises, including SMEs in Europe, is the "Continuing Vocational Training Survey", CVTS for short. The CVTS is conducted every five years, previous survey years are 1995 and 2000. The following analysis is taken from the 2005 survey, CVTS3. ${ }^{2}$ CVTS collected data on Initial VET for the first time in 2005. Data collected on the activities of SMEs are rare, making these data valuable forms of analysis into the training activity behaviour of SMEs.

Other OECD countries collect data on the training activities of firms within their country. While these data sources are not directly comparable, they provide evidence of the effect the size of the firm has on the likelihood that firms will participate in, and provide vocational training to, their staff. This report presents data collected through CVTS and other OECD sources.

\section{SME participation in vocational training ${ }^{3}$}

Figure 1.1 shows the CVET participation rate for both the 1999 and 2005 CVTS. There is little change in the overall rate of participation in the EU region for SMEs between the two 
Figure 1.1. Participation rates of enterprises by size in Europe (1999 and 2005)

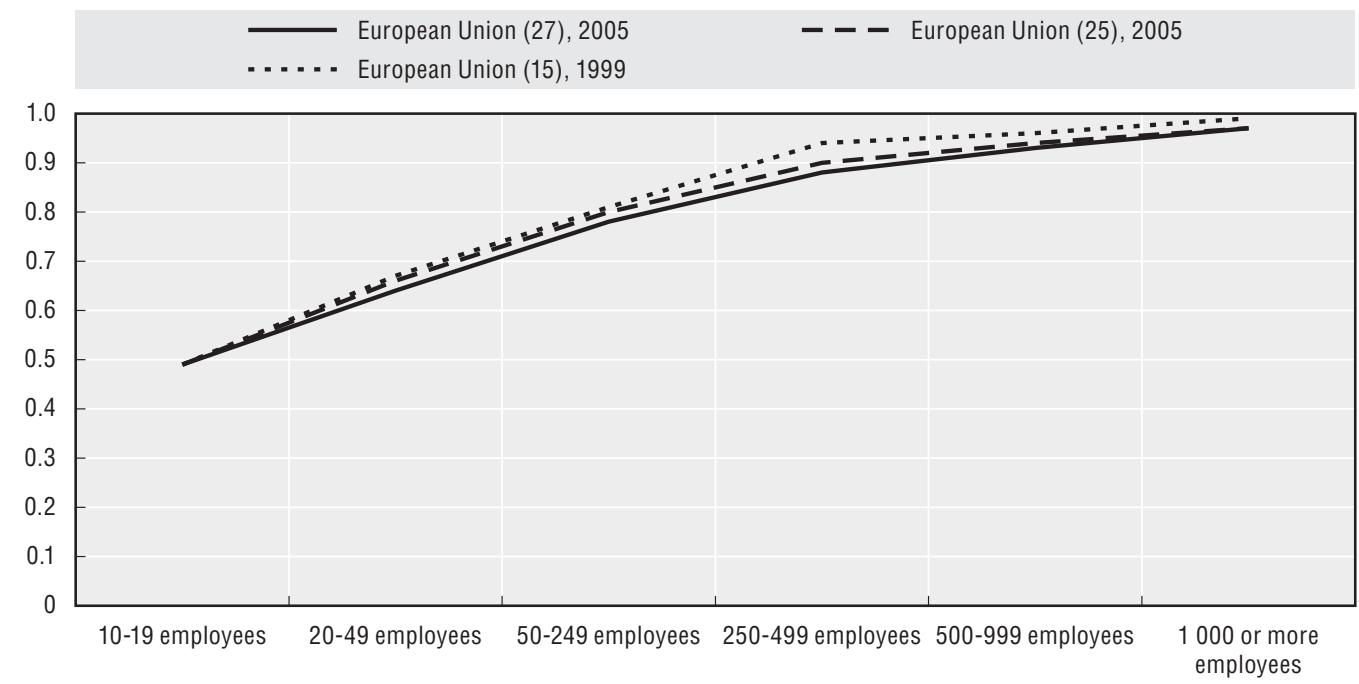

Source: EU Continuing Vocational Education and Training Survey 2009 *Survey year 2005 and EU Continuing Vocational Education and Training Survey 2004 *Survey year 1999.

surveys. The figures do show a small percentage decrease in CVET participation within large firms with 250-500 employees and the later two categories of large firms. The next CVTS survey in 2011 will indicate how this trend evolved and the financial crisis' impact on participation rates. $^{4}$

Figure 1.2 shows the percentage rate of firms participating in CVET by size of firm in Europe. $^{5}$ Small firms (defined as firms with 10 to 49 employees) have the lowest participation rates in CVET across all of the countries. Large firms (defined as firms with more than 250 employees) have the largest rates of participation in CVET. There is, however, significant difference between countries in the CVET participation rates of firms depending on the size of the firm.

Figure 1.2. Participation in vocational training by size of firm in Europe (2005)

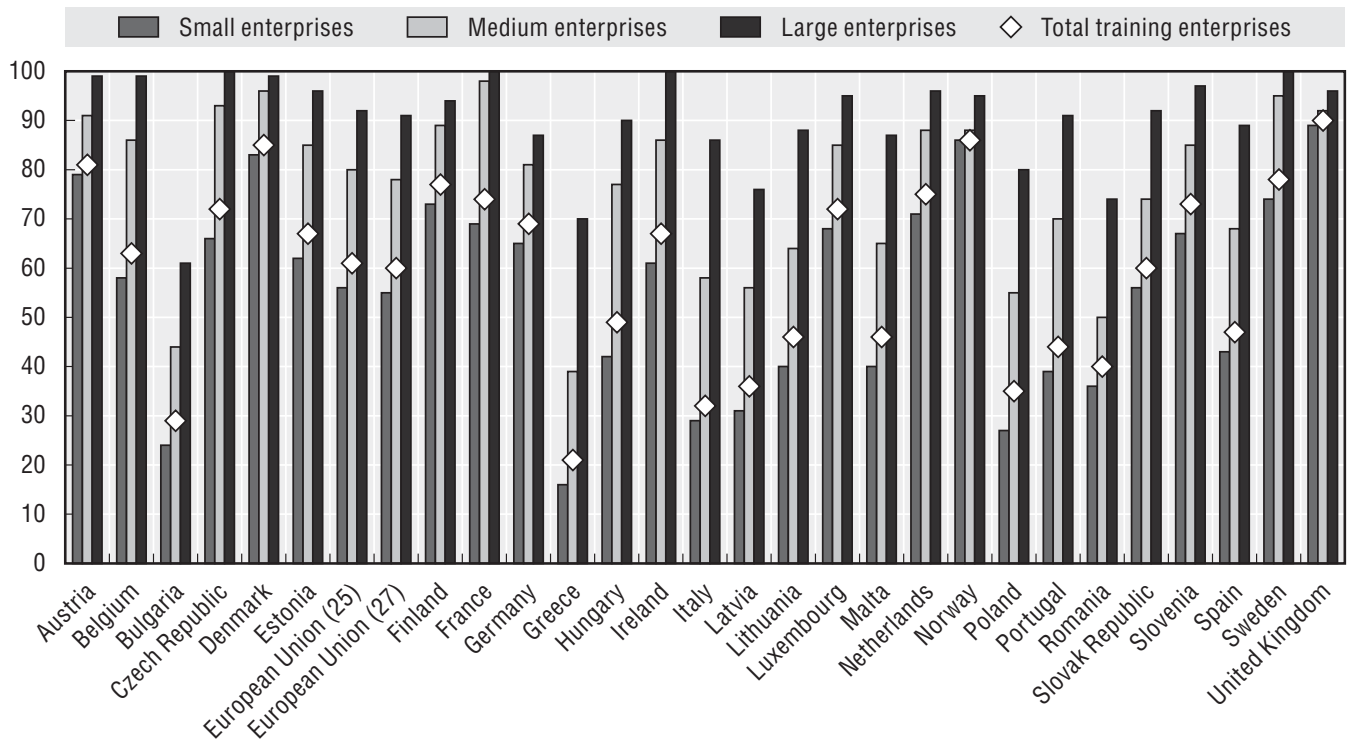

Source: EU Continuing Vocational Education and Training Survey 2009 *Survey year 2005. 
From analysis of the CVTS3 data (shown in Figure 1.2), in the small firm category, Greece had the lowest level of CVET participation, with only $16 \%$ of small firms engaging in CVET. Other countries with low levels of CVET undertaken by small firms include Bulgaria $(24 \%)$, Poland (27\%), Italy $(29 \%)$ and Latvia (31\%). At the other end of the scale, the United Kingdom had the highest level of CVET participation by small firms - with $89 \%$ of small firms listed as undertaking CVET enterprises. Norway (86\%), Denmark (83\%), Finland (73\%) and Sweden (74\%) also had high levels of participation.

For medium sized firms, the rate of participation in CVET increases. Greece again has the lowest rate of participation with only $39 \%$ of medium sized firms in the CVTS nominating that they participated in CVET. All other survey countries had rates above $40 \%$ and in most cases above $50 \%$ (with the exception of Bulgaria with $44 \%$ ). The United Kingdom medium-sized firms also display high levels of participation (92\%), but France has the highest level of participation (98\%) and several other countries had participation rates above 90\%, including the Czech Republic (93\%), Denmark (96\%) and Sweden (95\%).

These results suggest two main findings. Firstly, that the rate of CVET participation in small firms is influenced strongly by country specific variables, potentially policy mechanisms. Secondly, that the participation rate of medium sized firms highlights the impact of increasing organisation size on CVET as well as country specific variables, i.e. that once firms become a certain size (more than 50 employees), this triggers increased participation in CVET.

The CVTS did not survey microfirms, or firms with less than ten employees. This means that for the majority of firms in OECD countries, no standardised source of data is available to assess microfirms' participation in training. The latest National Employer Skills Survey for England (NESS) in 2009 surveyed 79000 employers on their training activities. This survey includes microfirms (firms employing two or more employees) as part of their sample.

The NESS survey does not use the same categories of business size, and collects information on training based on the place of training (i.e. on-the-job training or off-thejob training), but the results for the smallest firms, microfirms, are clear. Almost half of firms with two to four employees (45\%) participated in no training during 2009, with a further $16 \%$ only conducting on-the-job training (NESS, 2009). Importantly, the results also show that these smallest firms also have the highest levels of off-the-job training across all the company size categories.

\section{Types of vocational training provided}

The CVTS asked companies questions about the type of CVET training they provided or participated in during the reference year (2005). CVET includes training in the form of courses, but also activities such as: attending conferences, workshops, lectures and seminars; ${ }^{6}$ job rotations and secondments; ${ }^{7}$ learning and quality circles; ${ }^{8}$ self learning; ${ }^{9}$ and training at workstations.

Figure 1.3 shows that continuing vocational training courses were the most popular type of CVET used by firms of all sizes. More than $50 \%$ of large firms also used conferences, workshops, lectures and seminars, and training at workstations to provide CVET to employees. SME firms also favoured these methods, although at lower usage levels.

More internally focused and organised CVET such as job rotations, learning and quality circles, and self-learning were used extensively in larger firms, but not often used in SMEs (less than 20\%). This implies that with these forms of CVET there may be a need for a certain critical mass of employees in order to make it viable. 
Figure 1.3. Types of vocational training by size of firm in Europe (2005)

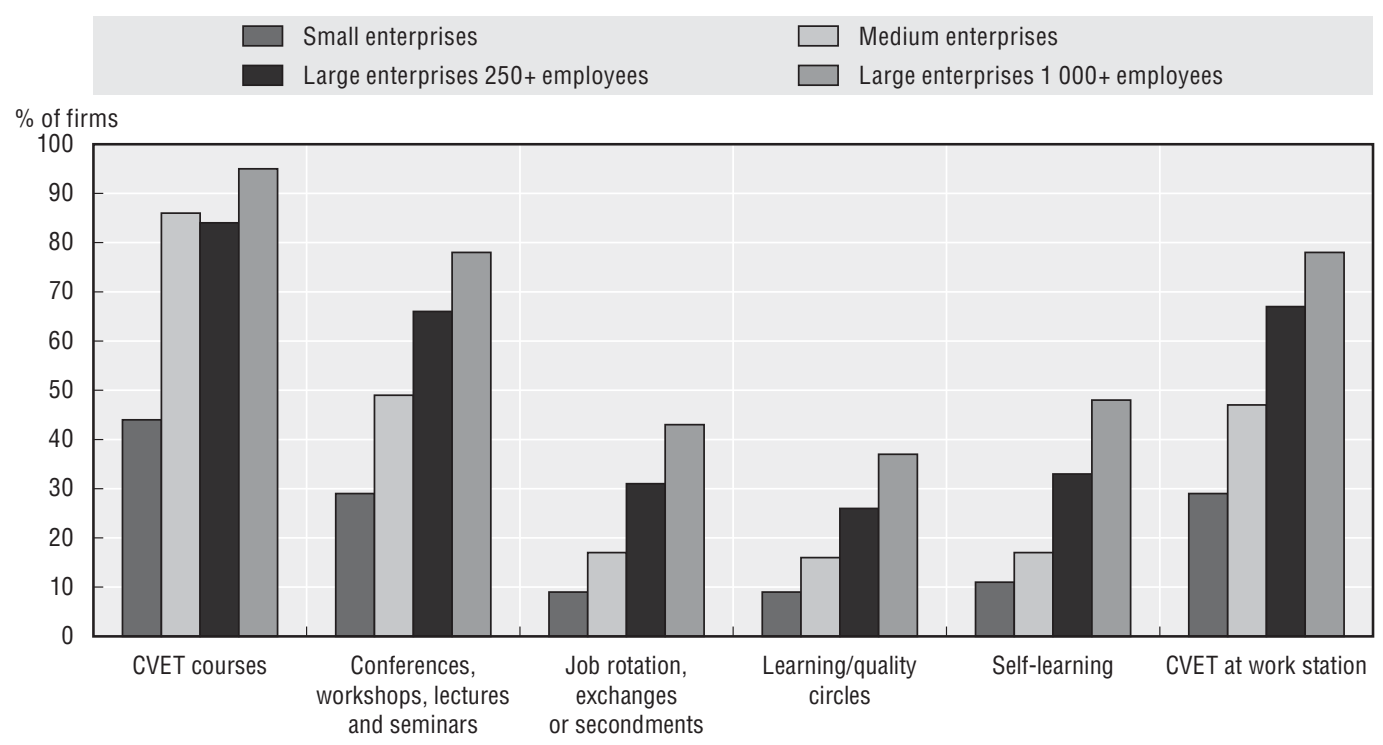

Source: EU Continuing Vocational Education and Training Survey 2009 *Survey year 2005.

\section{Participation in initial VET}

Apprenticeships are one of the oldest and most established forms of initial vocational education, typically involving a contract for a period of two to four years leading to a formal qualification. During this period the apprentice receives formal training as well as on-thejob training and experience (OECD, 2009).

Figure 1.4 shows apprentices as a percentage of the labour force. The figure demonstrates that there are national differences in the number of apprentices. This can be traced back to very different institutional arrangements for apprentices. For example, in Switzerland, the size of the firm can affect the conditions of the training provision; in smaller firms an apprentice and master training relationship predominates, whereas in larger enterprises, apprentices spend up to $40 \%$ of their time in special workshops and training centres.

Figure 1.4. Apprentices as a percentage of the labour force

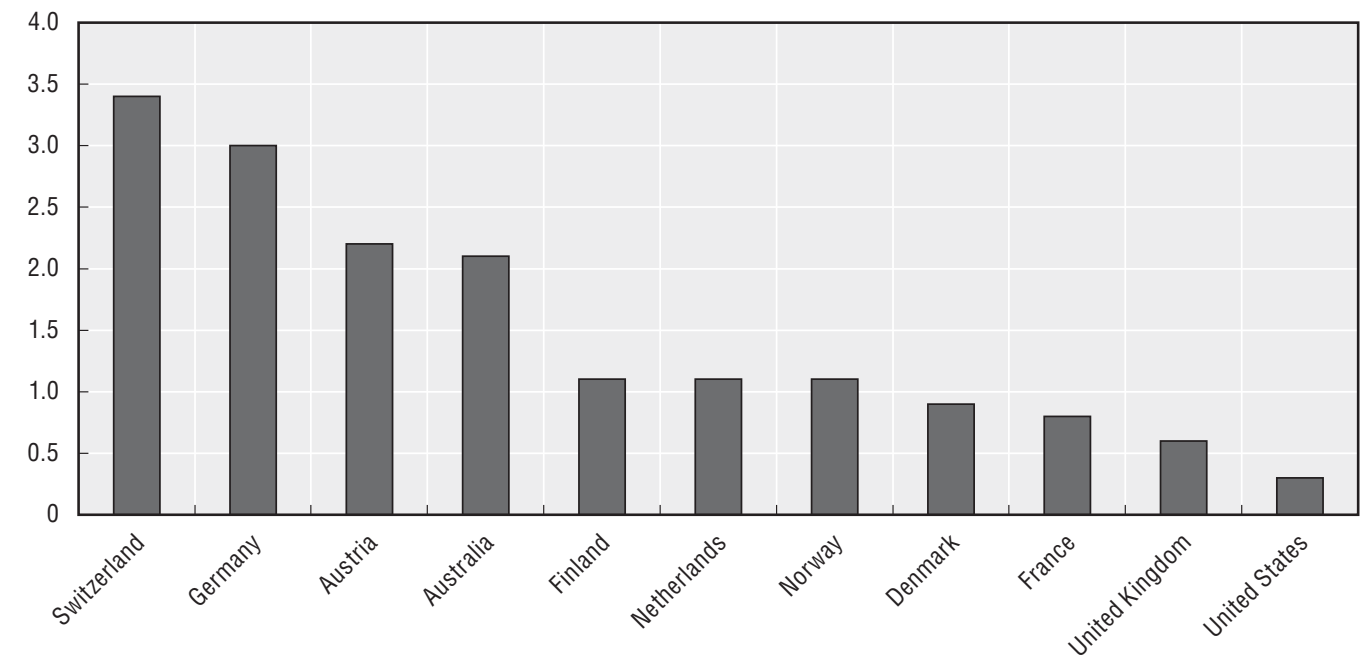

Source: NCVER (2005) using US Department of Labour and Cedefop data. 
In Australia, there is also evidence that the number of apprentices increases with the size of the firm, with larger firms having a higher frequency of apprenticeships. More than $90 \%$ of microfirms (five or less employees) and more than $86 \%$ of firms with $10-19$ employees do not have any apprentices, whereas $48 \%$ of larger firms (100+ employees) have apprentices in their enterprise.

\section{Reasons firms may not provide training}

When companies that did not participate in training were asked the reasons why they did not, responses were similar across companies of all sizes, as shown in Figure 1.5. The main reasons given for not participating in CVET were:

- The existing skills and competence of the persons employed corresponded to the current needs of the enterprise.

- People were recruited with the skills needed. This suggests that for non-training enterprises, recruitment rather than training provides the skills set for the firm. This strategy may prove adequate for industries with stable knowledge bases, but would not be appropriate for industries with rapidly evolving or changing knowledge bases.

Figure 1.5. Reasons for not providing training (Europe, 2005)

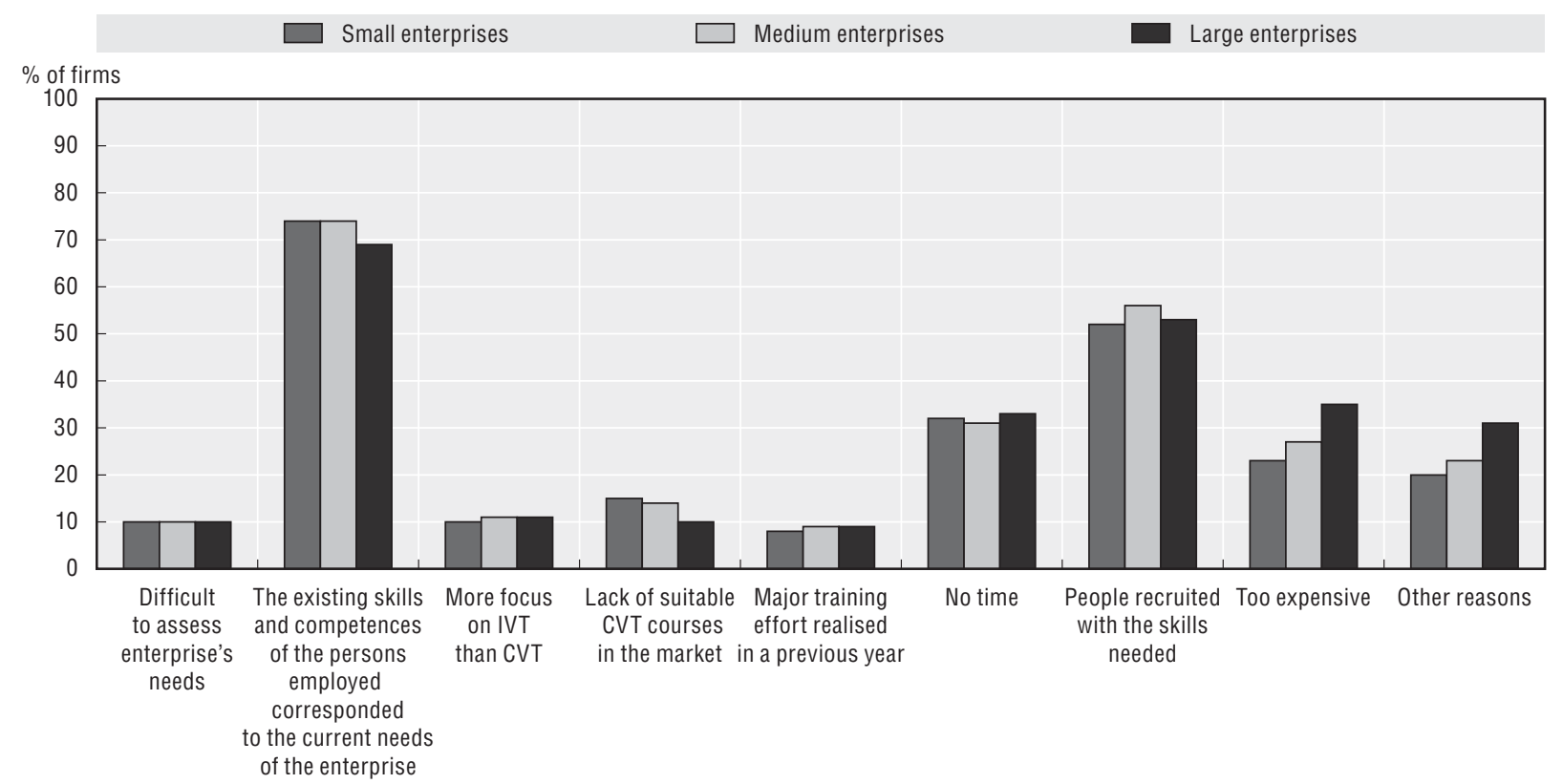

Source: EU Continuing Vocational Education and Training Survey 2009 *Survey year 2005.

The next two reasons given for not participating in CVET were, "no time" and "too expensive". Surprisingly, the cost of training was more an issue for large firms that small firms, however, it is possible that this is more a reflection that there are only a small number of large firms that are non-training enterprises.

Other reasons given for non-training include: the difficulty in assessing the enterprise's needs and hence the training needs; the firm having more focus on Initial VET (apprenticeships) than CVET; or that the firm had conducted a major training effort in the year prior to the survey reference period. In most cases, these reasons attracted less than $10 \%$ of responses. 
From this chart, a number of conclusions can be drawn. Clearly, all firms that do not participate in continuing vocational education do so because they believe they either already have or can recruit the skills their firm requires. Although the percentage response rates across the three categories of company (small, medium and large) are much the same, we know from analysis presented earlier (Figure 1.4) that many more large firms engage in CVET compared with SME firms. Thus, while the response rates outlining reasons for not providing training may be similar, for large firms, they only reflect the results of a much smaller number of firms; there are many more SMEs that rely on recruitment to procure skills than there are large firms doing this. When this analysis is examined in the context of figures discussed earlier regarding the future projected job growth areas (knowledge and skills intensive occupations), and the skills shortages that will occur in these areas, SMEs are going to be less able to rely on recruiting staff with required skills in the future, because there will be more competition for these skilled people in the labour market.

The response, "difficult to assess enterprise's need" attracted less than $10 \%$ of responses. This could suggest two alternatives: either firms (particularly SMEs as we are referring to a larger sample) have no difficulties assessing their future skills needs; or, SMEs who are not providing CVET and are instead relying on recruiting skilled staff have not had to properly assess their skills needs in regard to training. With a competitive labour market for knowledge and skills intensive employees this scenario may change in the future. Skills needs assessments and the provision of CVET within a business are not activities that firms can pick up overnight. Firms need to develop skills and dedicate resources to CVET over a period of time in order to capture the benefits of CVET activities.

\section{Processes of training provision in firms}

This section looks in greater detail at the processes of training provision in firms that did provide CVET. These processes include: the use of tools; both internal and external providers of training; and the degree to which training is formalised within the firm. The CVTS asked companies questions regarding their use of training plans, training centres, and the types of resources provided within the firm (training budgets and dedicated personnel) for CVET.

There are clear differences in firms' use of a training plan based on company size, with $28 \%$ of small firms, $47 \%$ of medium firms and $70 \%$ of large firms using training plans to guide their provision of training to their employees. Policy instruments that facilitate the development of this role in SMEs could offset the lack of dedicated resources to training management.

These differences are also reflected in the firms that had dedicated human resources responsible for organising and/or delivering training within the firm. Across the EU27 region, $36 \%$ of small firms, $52 \%$ of medium firms and $73 \%$ of large firms had dedicated people within their organisation to manage CVET. Across the EU27 region there was also significant variation between countries in the use of specific human resources (HR) training resources. Firms in Italy, Luxembourg, Portugal and the United Kingdom showed higher levels of dedicated HR for training activities than other countries. However, in the case of Italy and Portugal, this should be viewed within the context of low SME training rates reported earlier. 
There is also evidence from Australia confirming this variation in quality of training according to the size characteristics of the firm. Research suggests that small firms are unlikely to have dedicated training staff (Hawke, 1998) and training offered tends to be unplanned (Vallence, 1997), informal and company specific (Seagraves and Osborne, 1997). While workplace training needs to yield benefits to employers in order to encourage them to offer sufficient training places, it should not be so organisationally specific that it inhibits future professional mobility (OECD, 2009).

When looking at the external resources of which firms make use for the provision of CVET, such as external training centres for the provision of all or part of CVET, or the use of external advisory services to provide training, the same characteristics related to size of firm exist, but not to the same extent. In the use of external resources, it might be expected that SMEs would seek to use external resources to overcome the critical mass/size liabilities that may limit their ability to offer training to their staff. However, this did not prove to be the case. Of all the enterprises that provided CVET, only $13 \%$ of small firms and $18 \%$ of medium firms made use of an external training centre for part or full provision of this training, compared with $24 \%$ of large firms. There were some notable differences: in Denmark, $56 \%$ of small and $78 \%$ of medium firms used external training centres; and in Italy the usage figures were also high, with $29 \%$ of small firms and $39 \%$ of medium firms utilising external training centres.

The results of the use of external advisory services were more even, as shown in Figure 1.6. Indeed, $38 \%$ of small firms used external advisory services occasionally to meet their CVET needs, with a further $18 \%$ using them on a more frequent basis (often or always). $43 \%$ of medium sized firms used these services occasionally, with a further $20 \%$ using them more often. When compared with large firms (46\% occasionally and $26 \%$ more frequently), there is not the same large degree of difference seen in other CVET data. This suggests that external training resources are viable tools for SMEs in providing CVET.

Figure 1.6. European training enterprises using external advisory services (2005)

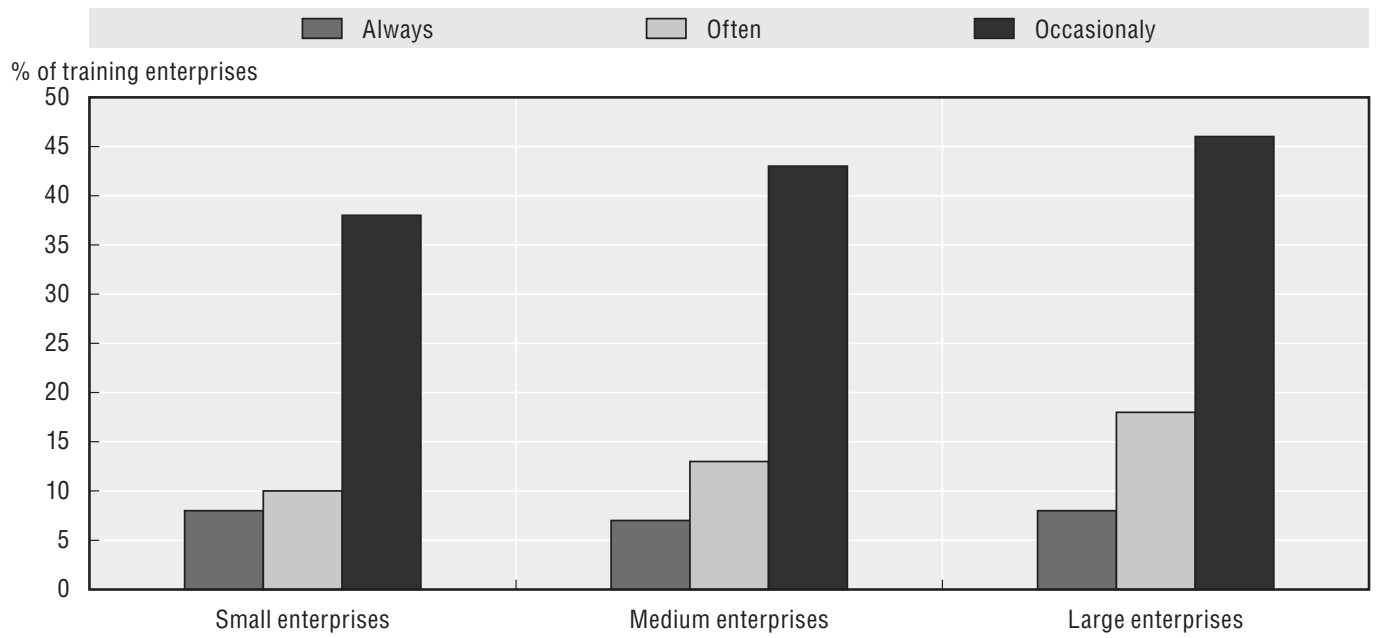

Source: EU Continuing Vocational Education and Training Survey 2009 *Survey year 2005.

\section{Assessing skills requirements and undertaking training planning}

This section presents data regarding how firms assess their training needs, and plan for training and skills development in the future. Figures 1.7 and 1.8 show the percentages of 


\section{Figure 1.7. Percentage of European enterprises assessing staff training needs (2005)}

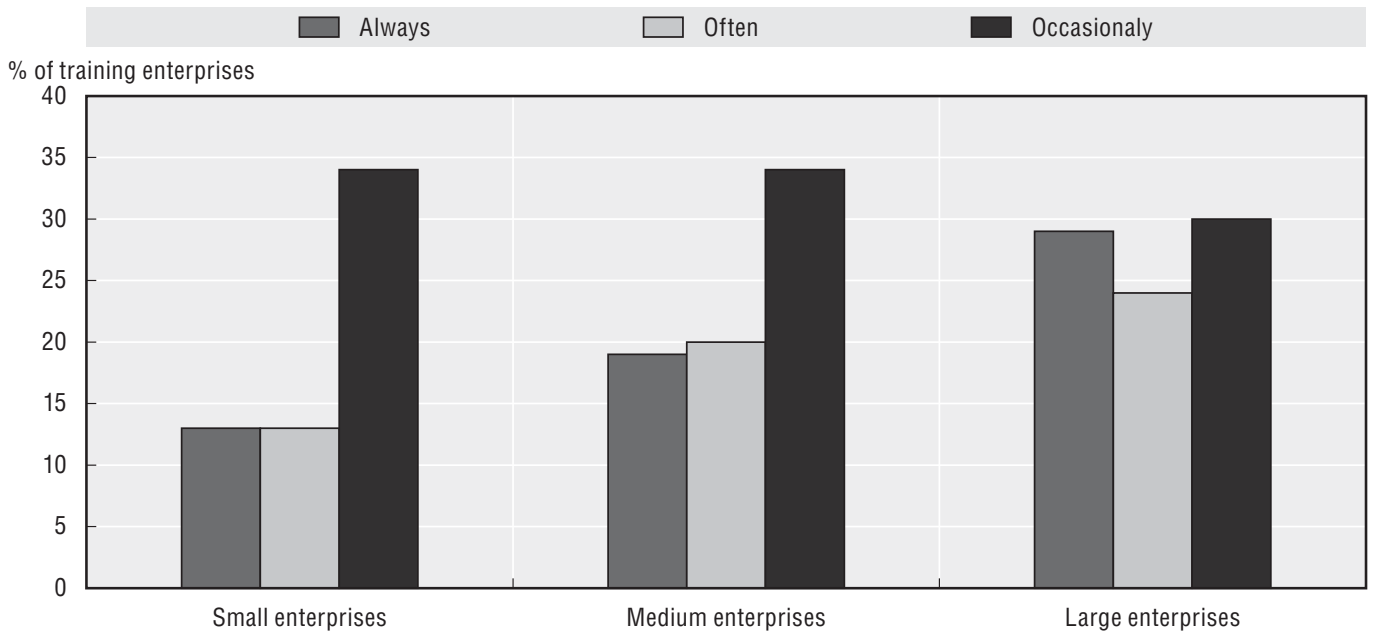

Source: EU Continuing Vocational Education and Training Survey 2009 *Survey year 2005 (Eurostat 2009).

Figure 1.8. Percentage of European enterprises assessing future skills needs (2005)

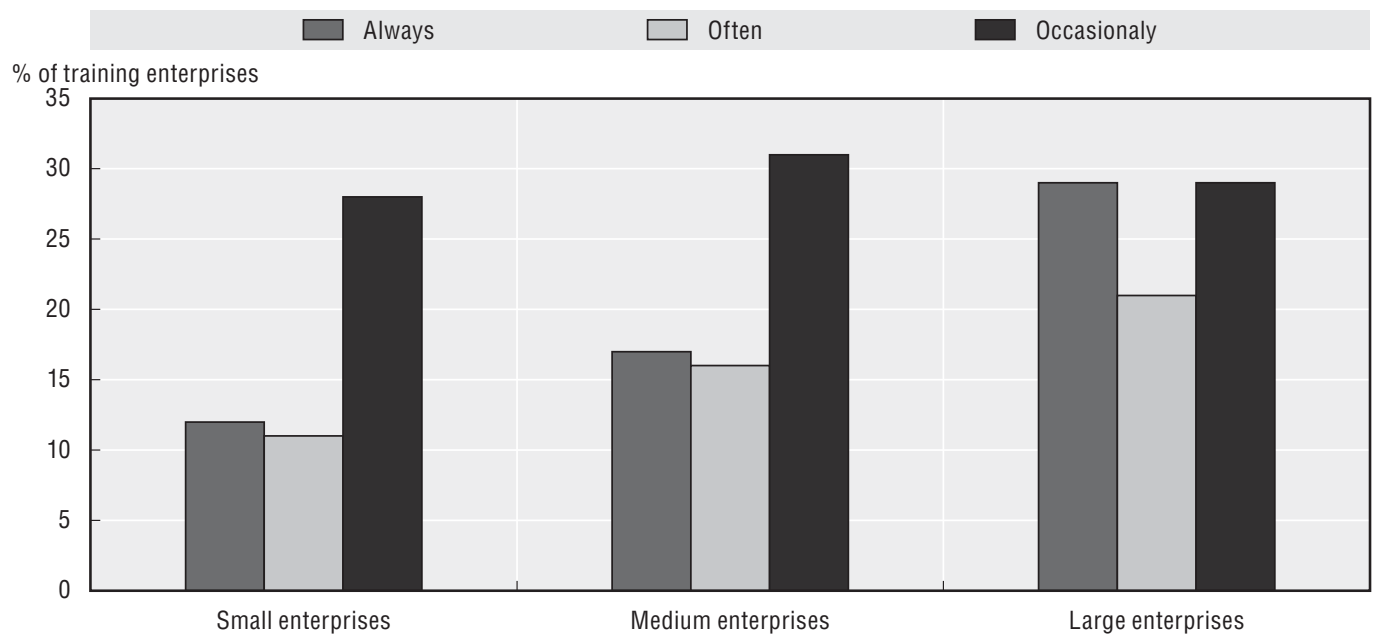

Source: EU Continuing Vocational Education and Training Survey 2009 *Survey year 2005 (Eurostat 2009).

firms that assess the current training needs of their staff and the future skills requirements of the firm, and the frequency of this assessment. Company size characteristics again appear to be an influential force on current and future training and skills assessments.

Almost two-thirds of small firms (60\%), $72 \%$ of medium sized firms and $82 \%$ of large firms in the EU27 region undertake assessments of the current training needs of their staff. Similarly, just over half (51\%) of small firms, $65 \%$ of medium sized firms and $79 \%$ of large firms assess the future skills needs of their firm. Although these statistics point to the fact that a majority of firms of all sizes assess their current and future skills needs, what is telling about the differences between the company size categories, is the frequencies with which these assessments are being made. In SME firms, these assessments are more likely to be occasional, whereas in large firms these assessments are routine and happen with regular frequency. The assessment of both current and future skills needs shows the level 
of preparedness that firms have to deal with industrial evolution and changing patterns of knowledge. Ad hoc or incidental skills assessments put SMEs in a weakened position for dealing with such changes.

However, when the reasons influencing the scope of firms' CVET activities are analysed, the lowest stated influence factor for SMEs is difficulties in assessing the skills needs of the firm. It also appears that size of the firm has little influence on the factors stated by firms as influencing the scope of their training activities. The twin factors of "no time" and "no need" rated the highest in each of the different company size categories, followed by "too expensive" (with more larger than smaller firms giving this response), while "lack of suitable training" was listed by more than $20 \%$ of firms in each of the size categories.

\section{Effect of public policy measures}

This section looks at the influence of public policy measures on firms' training activities. In the CVTS, participating firms were asked about the positive impact of certain public policy measures on their training activities. Figure 1.9 shows the results for the three company size categories.

For SMEs across the EU27 region, the most powerful public policy actions that impacted (positively) on their training activities were: the provision of recognised standards and frameworks for qualifications and certificates; and financial subsidies in covering the costs of training. These were also the most influential factors for large businesses, but at much higher percentage levels (provision of recognised standards and frameworks was listed as having a positive impact on training activities in $32 \%$ of large firms compared with $18 \%$ of small firms and $23 \%$ of medium sized firms).

\section{Figure 1.9. Public measures' impacts on training for European enterprises (2005)}

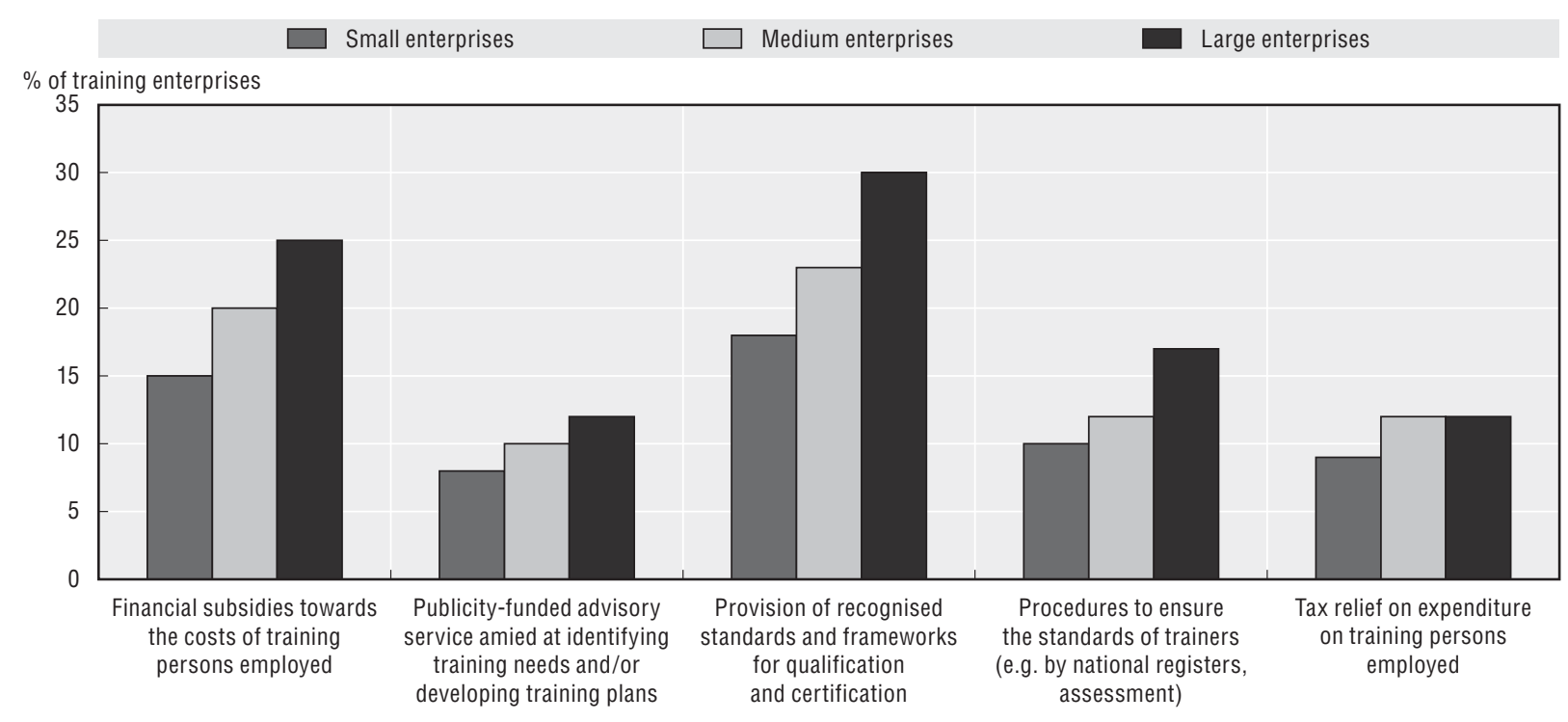

Source: EU Continuing Vocational Education and Training Survey 2009 *Survey year 2005 (Eurostat 2009).

The least influential factor in all company size categories was "Publicly funded advisory services aimed at identifying training needs and/or developing training plans". Only $12 \%$ of large firms, $10 \%$ of medium sized firms and $8 \%$ of small firms listed this as an important factor influencing the scope of their training activities. Re-examination of previous data seems to indicate that the reasons for this small level of impact may, however, be different 
across the company size categories. Because most large firms had training plans, and regularly and formally assessed their training needs, the low rating in this instance could suggest a lack of need for the public measure. Whereas in the case of the SMEs, which in previous charts demonstrated lower levels of usage of training plans, and more ad hoc and occasional skills assessments, the low level of influence of this public measure could be a result of lack of knowledge about the measure, or lack of accessibility of the measure.

Public policy makers are also interested in targeting policy towards specific groups of people that may be disadvantaged in the labour market. Figure 1.10 examines the targeting of CVET by companies to specific employee groups, such as ethnic minorities, handicapped employees, and employees on fixed term contracts or at risk of losing their job with the EU27 region. As would be expected, large firms show higher levels of provision of specifically targeted CVET in all but one case - medium size firms have higher levels of training targeted at ethnic minorities than do large firms (34\% compared with $32 \%$ respectively).

Figure 1.10. EU27 enterprises providing focused training for specific employees (2005)

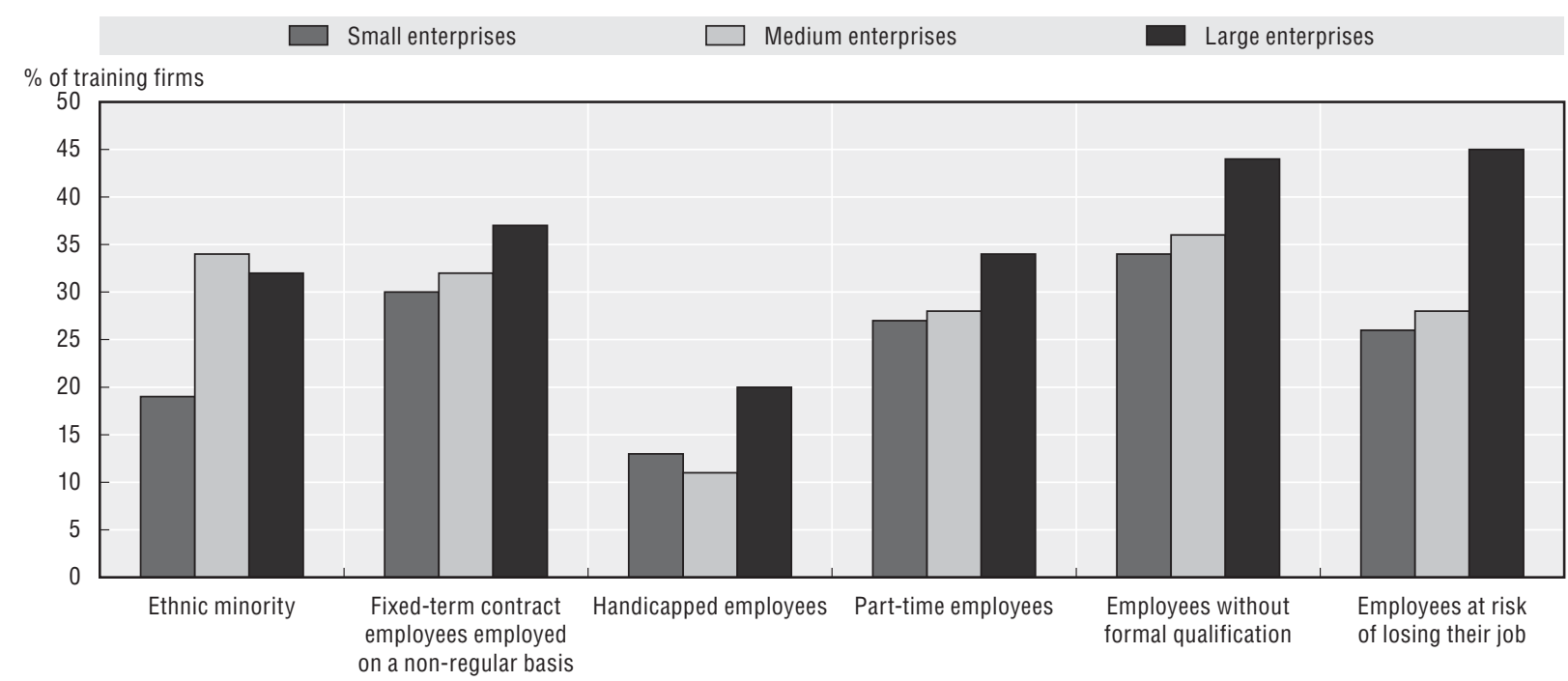

Source: EU Continuing Vocational Education and Training Survey 2009 *Survey year 2005 (Eurostat 2009).

Over $40 \%$ of large firms provide specifically targeted CVET to employees without formal qualification and employees that are at risk of losing their jobs, with a third of large firms also providing targeted training to part-time, fixed term and ethnic minority employees. SMEs had lower levels of targeted training, with the areas of highest activity being directed towards employees with no formal qualifications, and employees on fixed term contracts. National differences also exist and suggest different regulatory requirements are placed on firms of different sizes in regards to such targeted training.

It is also interesting to note that the highest level of specific training provided by SMEs was in regard to employees without formal qualifications, suggesting that targeted training may be provided by employers in order to give employees formal qualifications. Referring back to the first section and overall impetus for this research - the assumption that SMEs were less likely to participate in CVET and, where they did participate in training, that it was more likely to favour managers and higher skilled employees with formal qualifications - these data provide a positive counter indication regarding the levels of training provision for lower skilled workers to gain formal qualifications. 


\section{Conclusions and policy implications}

There is clear evidence that workforce size is an important determinant of a company's behaviour in relation to its participation in training and skills development. The 2005 Continuous Vocational Training Survey 3 (Eurostat, 2005) conducted by the European Commission, showed that only $50 \%$ of small firms participated in formal CVET compared with $90 \%$ of large firms. These figures are unchanged from the previous survey in 1999 . While there are significant national differences in CVET participation across the EU (Greek small firms had the lowest levels of participation at 16\% compared with the United Kingdom small firms that had the highest, with 90\%), in all countries, SMEs had lower levels of CVET activity than larger firms. These results are also reflected in data from Australia and New Zealand.

This chapter outlined some of the factors that SMEs take into account when making decisions on staff training, specifically:

- Internal training programmes such as learning circles, and job rotation, exchanges or secondments have limited participation by SMEs (probably due to their lack of critical mass) and it is therefore suggested that these firms could benefit from a network approach, utilising members of their skill ecosystem to generate similar economies of scale for training activities available to larger firms. For example, several SMEs could join forces to organise learning circles or exchanges of personnel within an industry cluster or value-chain.

- Recruitment is the main process for introducing and updating skills in the firm. This is an important barrier to innovation and competitiveness within firms if the sector in which the firm operates evolves rapidly and needs to adjust its knowledge base. The Cedefop (2010) report quoted in the introduction noted that employment growth over the next 10-15 years will predominantly be in knowledge and skills intensive occupations, and that the labour market for these employees will be strong. SMEs will be less able in the future to recruit employees to fulfil their skills needs, and therefore plans for the development of their workforce's skills need to be part of SME's business operations.

- Assessment of both current and future skills needs appear to be more casual in SMEs than in large firms where these assessments are routine and happen with regular frequency. This is especially critical for SMEs because, by failing to undertake skills needs consistently and systematically, they are risking lost competitiveness in the face of industry evolution and changing patterns of knowledge. As a consequence, SMEs might face new market challenges in a weak position and with increasing vulnerability. The evidence shows the critical need to assess the means and approaches for SMEs today towards their skills development, as this may differ from traditional measures of formal training participation.

\section{Notes}

1. The report OECD (2010), SME Participation in Formal Vocational Education and Training (VET) in Selected OECD Countries provides greater detail of the statistical analysis.

2. CVTS3 was conducted in 2006 for the reference period of 2005. The design of CVTS3 does not necessarily correspond with earlier versions of the survey, therefore longitudinal analysis is difficult.

3. CVTS data does not include firms of 10 or less employees within the survey sample. 
4. At the time of preparing this report, data from the 2010 CVTS, for which data is collected across 2011-12, was not available. However, data presented here is still a valid source of trends in SMEs' participation in training.

5. The charts presented in this report primarily relate to the EU27 region unless otherwise stated.

6. Attendance at conferences, workshops, lectures and seminars are only counted as vocational training actions if the primary purpose of an employee attending is training/learning (Eurostat, 1999).

7. Job rotation and exchanges with other enterprises are only CVET if these measures are planned in advance with the specific purpose of developing or improving the skills of employees involved (Eurostat, 1999).

8. Learning circles are groups of employees who come together on a regular basis with the primary aim of learning about the requirements of workplace organisation, work performance and the workplace itself. It is a form of individual learning within groups.

Quality circles are working groups with the aim of discussing and solving problems regarding production and the workplace. Participants have to be integrated within the planning and controlling procedures of the enterprise (Eurostat, 1999).

9. Self learning through open and distance learning courses, video/audio tapes, correspondence courses, computer-based methods (including the Internet) or the use of a Learning Resources Centre is only continuing vocational training if it is the trainee/learner who manages the training time and the place at which the learning takes place (CVTS2, 1999).

\section{References}

Cedefop (European Centre for the Development of Vocational Training) (2010), Jobs in Europe to become more knowledge and skills-intensive, European Centre for the Development of Vocational Training (Cedefop) Briefing Note, February 2010, Cedefop, Thessaloniki (Pylea).

Eurostat (European Statistical System) (1999), Continuing Vocational Training Survey 2, European Commission, Brussels.

Eurostat (2005), Continuing Vocational Training Survey 3, European C Participants in a Work based Learning Programme: Small and Medium Enterprises ommission, Brussels.

Hawke, G. (1998), "Learning, workplaces and public policy" in J. McIntyre and M. Barrett (eds.), VET Research: Influencing Policy and Practice, proceedings of the first national Conference of the "Australian Vocational Education and Training Research Association", Sydney.

NESS (National Employer Skills Survey) (2009), National Employer Skills Survey for England 2009, NESS, London.

OECD (2008), Leveraging Skills and Training in SMEs, CFE/LEED(2008)6, OECD, Paris.

OECD (2009), Learning for Jobs, Initial Report, OECD, Paris.

OECD (2010a), SME Participation in Formal Vocational Education and Training (VET) in Selected OECD Countries, CFE/LEED (2010)6, OECD, Paris.

Seagraves, L. and M. Osborne (1997), "Participants in a Work-based Learning Programme: Small and Medium Enterprises and their Employees" in Good Thinking: Good Practice - Research Perspectives on Learning and Work, 5th Annual International "on Post-compulsory Education and Training", Griffith University, Brisbane.

Vallence, K. (1997), “Training one-to-one: Out of sight, out of mind" in Good Thinking: Good practice Research Perspectives on Learning and Work, 5th Annual International Conference on "Postcompulsory Education and Training", Griffith University, Brisbane. 